\title{
Modelling and arrangement of composite panels in modernized freight cars
}

\author{
Marek Płaczek ${ }^{1, *}$, Andrzej Wróbel ${ }^{1}$, and Maciej Olesiejuk ${ }^{2}$ \\ ${ }^{1}$ Silesian University of Technology, Faculty of Mechanical Engineering, Institute of Engineering \\ Processes Automation and Integrated Manufacturing Systems, Konarskiego 18A, 44-100 Gliwice, \\ Poland \\ ${ }^{2}$ IBS Poland Sp. z. o. o, PLM Support Department, Jagiellońska 4, 44-100 Gliwice, Poland
}

\begin{abstract}
A process of modelling in a CAD system and designing of arrangement of composite panels used for freight cars' body shell protection against corrosion and for easier unloading of transported cargo in winter conditions is presented in this work. Arrangement of used composite panels was designing in order to fulfil assumed criteria and thus to improve the process of freight cars modernization during periodic repairs.
\end{abstract}

\section{Aim of the research work and state of the art}

The main problem during exploitation of freight cars designed for coal transport is corrosion of the body shell. The goal of the work was to elongate the period between periodic repairs (by better corrosion protection) and improve conditions of exploitation of modernized freight wagons (for example easier unloading during winter conditions - no freezes of the charge to the freight wagon body shell). The proposed solution is application of composite panels to the freight car's body shell. The main causes of degradation of freight wagon body are acid rains, sulphur precipitated from coal and mechanical damage occurring during loading and unloading Figure 1. The repair of those wagon must be conducted every few years and the process itself is time consuming and expensive.

New materials and technology are solutions that can develop technical devices [1-5]. Also in case of railway transport there are a lot of research works carried out in order to develop this mean of transport. Some solutions proposed as a development of freight cars are applications of aluminium alloy or stainless steel [6,7]. Application of aluminium because of the high specific strength to weight ratio of aluminium enables increased payload and fuel savings as well as corrosion protection [6]._Applications of special types of stainless steel can also extend financial planning horizons when they consider maintenance and replacement as proposed authors in paper [7]. As they explain the true cost of ownership comparisons between several candidate materials - mild steel, conventional stainless and specialty stainless steel have repeatedly shown that replacement periods can be extended by as much as ten years with specialty stainless steels such as Cromgard. It can result in a very significant reduction in overall lifecycle cost. They

*Corresponding author: marek.placzek@polsl.pl 
claimed that during inspection of coal wagons built in specialty stainless steel it was proved that it can provide a projected ultra-long service life and require minimal maintenance. They inform that during inspection after years of exploitation of a typical vehicle from the fleet, which was completely built in specialty stainless steel, the hopper doors were found to be in a bright, smooth condition and no discernible metal loss was detected. The wear rate was consistent with the 40-year life expectancy required. The proposed stainless steel provides a very good resistance to corrosion and abrasion. It also allowing the construction of robust structures at relatively low weight what is very important in case of freight cars [7].Developments in composite materials for the rail industry is presented also in [8] where authors present current status and options for further cost effective weight savings in rail vehicles obtained by application of composite materials. Less weight and as a result less energy consumption is presented as one of the benefits brings by the composite materials application. This advantage can also be used in freight cars.

In the presented research work an application of the composite panels to the freight wagon's body shell was proposed as the solution that can solve mentioned problems during exploitation [9-14]. The overall thickness of the composite was $5 \mathrm{~mm}$ and the maximum width could not exceed $1200 \mathrm{~mm}$ due to manufacturing restriction. Composite panels were mounted on the body shell using rivet nuts. Each panel was fastened with twelve $\phi 8$ rivet nuts with the assumption that there were five rivets on each of the longer side. Due to corrosion of the wagon's shell, rivets were to be mounted on reinforced parts of wagon (elements of the frame - for example to posts). What is more the body shell of the modernized freight wagon was painted using an anti-corrosion agent, while the standard freight wagon body is not painted inside at all.
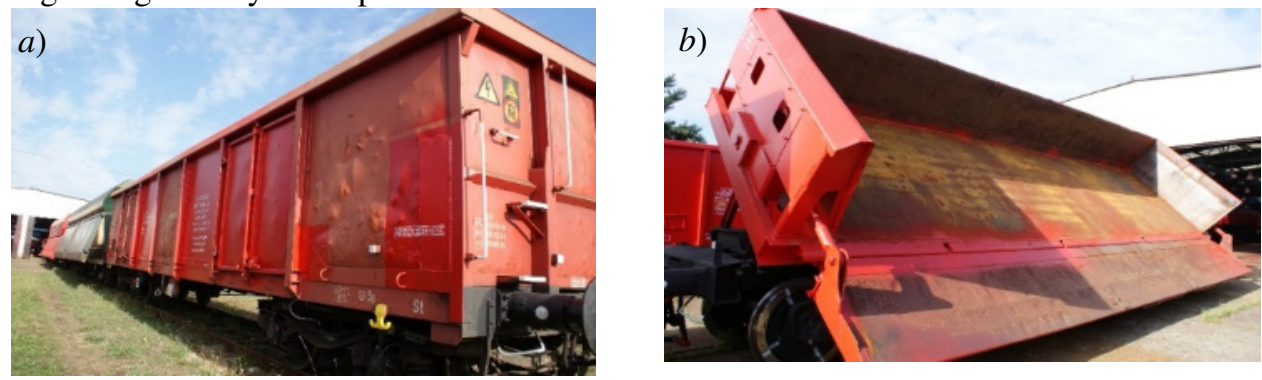

Fig. 1. EAOS 1415-A3 freight wagon $(a)$ and 418 V Dumpcar freight wagon $(b)$.

\section{Modelling of composite panels}

Composites modules were designed for two widely used in Poland freight wagons EAOS 1415-A3 and Dumpcar 418V. For the needs of this work, a 3D documentation of those wagons was prepared by Silesian University of Technology. The documentation was originally made in NX Siemens 8.5 software and then via STEP 214 ISO standard exported into CATIA V5-6R2014 software, which was the default work environment. The design process began with determining the actual interior dimensions of both freight wagons.

Additionally initial number of used composite modules taking into account criteria of their width and thickness was estimated. During this estimation manufacturing processes were also considered to provide most productive fabrication and limiting diversity of composite plates' sizes. Finite number, distribution and dimensions of plates were calculated with analytical method. Prior to the design process a material library was defined containing information such as Young's modulus, Poisson's ratio, density, cured thickness and width about used materials such as fiberglass and epoxy resin [Table 1]. Library was created in CATIA Material Library application. The design itself was conducted in dedicated application - Composite Design. 
Table 1.Materials specification.

\begin{tabular}{|l|c|c|}
\hline & Fiberglass & Epoxy resin \\
\hline Young's Modulus [GPa] & 8 & 3,5 \\
\hline Poisson's ratio & 0,31725 & 0,4 \\
\hline Density $\left[\mathrm{kg} / \mathrm{m}^{3}\right.$ ] & 2600 & 1170 \\
\hline Cured thickness [mm] & 0,46 & 0,088 \\
\hline Material width [mm] & 1200 & 1220 \\
\hline
\end{tabular}

At next stage sketches were made in Generative Shape Design application, which were then used to create planar surfaces. Those planar surfaces along their contour were to be used as composite basis. In Composite Design application defined a Laminate value which determined composite structure. In Composite Parameters dialog box materials to be used were defined as well as their order and orientation.

Following composite layers were defined:

I. Epoxy resin - thickness $0,088 \mathrm{~mm}$; orientation $0^{\circ}$

II. Fiberglass - thickness $0,46 \mathrm{~mm}$, orientation $-45^{\circ}$

III. Fiberglass - thickness $0,46 \mathrm{~mm}$, orientation $45^{\circ}$

IV. Epoxy resin - thickness $0,088 \mathrm{~mm}$; orientation $0^{\circ}$

V. Fiberglass - thickness $0,46 \mathrm{~mm}$, orientation $-45^{\circ}$

VI. Fiberglass - thickness $0,46 \mathrm{~mm}$, orientation $45^{\circ}$

VII. Epoxy resin - thickness $0,088 \mathrm{~mm}$; orientation $0^{\circ}$

VIII. Fiberglass - thickness $0,46 \mathrm{~mm}$, orientation $-45^{\circ}$

IX. Fiberglass - thickness $0,46 \mathrm{~mm}$, orientation $45^{\circ}$

X. Epoxy resin - thickness $0,088 \mathrm{~mm}$; orientation $0^{\circ}$

XI. Fiberglass - thickness $0,46 \mathrm{~mm}$, orientation $-45^{\circ}$

XII. Fiberglass - thickness $0,46 \mathrm{~mm}$, orientation $45^{\circ}$

XIII. Epoxy resin - thickness $0,088 \mathrm{~mm}$; orientation $0^{\circ}$

XIV. Fiberglass - thickness $0,46 \mathrm{~mm}$, orientation $-45^{\circ}$

XV. Fiberglass - thickness $0,46 \mathrm{~mm}$, orientation $45^{\circ}$

XVI. Epoxy resin - thickness $0,088 \mathrm{~mm}$; orientation $0^{\circ}$

As result total composite thickness added up to $5,128 \mathrm{~mm}$. Laminate value created in previous steps was then defined on a base surface. Result of defining the area where laminate will be applied was obtaining a surface-based composite plate design. Next stage assumed creating an associative solid from surface-based design. This solution provides an ability to modify the base surface, composite structure as well as its thickness, which would change the solid after an update. Although the resulting solid is associative with composite parameters it is created as object without history of its design and information about materials from which it was made of. The purpose of creating solid-based composite modules was to be able to create technical documentation of those object as well as ability to position them in the context of the wagon.

Provided freight wagon models were opened in Assembly Design application and mounting holes in wagon floor and plating were made. Holes were created using "Hole" function and their diameter was set to $11 \mathrm{~mm}$ as stated in their specification. In next step mounting holes were duplicated using "Rectangular Patter" to fulfil the requirement of twelve instances per composite plate. More holes were placed in a manner to provide $3 \mathrm{~mm}$ clearance between each plate.

Similarly, holes in the composite modules were created, which were to be used as engineering connection references in later stages of the design. Then "Multi Instantiation" function was used to duplicate and position identical composite plates in the context of the wagon. During described process of multi instantiation $3 \mathrm{~mm}$ clearance between models was also taken into consideration. Comparable actions were made in terms of symmetrical 
objects in the context of wagon. Additional symmetry plane were made and "Assembly Symmetry Wizard" was used to instantiate objects in the wagon. At the next stage engineering connections of coincidence and contact were defined between the composite plates and the body of the wagon to provide stability to the assembly.

At the final stage of the design process rivet nut model was created in Part Design application which was instantiated in wagon context. Rivet nuts were positioned using coincidence and contact engineering connections. Composite plates in EAOS 1415-A3 wagon were mounted using 462 rivet nuts which position were defined using 924 engineering connections. Similarly, 168 rivet nuts were used in context of 418V Dumpcar assembly positioned using 336 engineering connections. After design process was completed technical documentation was made in Drafting application. Each composite plate was dimensioned according to ISO 1101 standard.

\section{Number and arrangement of composite panels}

Technological processes which describe the manufacturing of composite plates define design requirements which should be taken in consideration. One of the most critical requirements was maximum width of the plate. Although it is possible to obtain composites of greater width using the same materials the process itself require using transition zones which makes it more expensive and time consuming.

Another restriction connected with possible number of composite panels was corrosion of wagon plating. What is more creating mounting holes in already severely damaged wagon plating could cause significant reduction of durability that is why size of composite modules had to be similar to distance between reinforcing posts. Described solution provided ability to create mounting holes in the least fragments of wagon body.

Last but not the least requirement was defined by repair processes which are usually done in groups of two people. That is why dimensions of composite plates should allow workers to handle and mount them in the interior of the freight wagon.

Taking into consideration all project requirements concerning composites plates' size and needed clearance between them following configurations were obtained:

- $418 \mathrm{~V}$ Dumcar - to cover interior of the wagon body eighteen composite plates were used in four different sizes:

1. Four plates were used to cover middle of side walls, two plates per side (longitudinal cross-section of the 418V Dumpcar wagon - Figure $2 a$ );

2. Four plates were used to cover the ends of side walls, two plates per side (Figure $2 a$ );

3. Two plates were used to cover the front and back walls, one plate per side (top view of 418V Dumpcar wagon - Figure $2 b$ );

4. Eight plates were used to cover floor of the wagon (Figure $2 b$ ).

- EAOS 1415-A3 - to cover interior of the wagon body forty three composite plates were used in eight different sizes:

1. Eleven plates to cover the floor of the wagon (top view - Figure $3 a$ );

2. Four plates to cover front and back walls, two plates per side (transverse cross-section of EAOS 1415-A3 wagon - Figure 3b);

3. Eight plates to cover the ends of side walls, four plates per side (longitudinal crosssection of EAOS 1415-A3 wagon - Figure 3c);

4. Eight plates to cover the middle of side walls, four plates per side (Figure 3c);

5. Four plates to cover the middle of side wall, two plates per side (Figure 3c);

6. Four plates to cover plating above doors, two plates per side (Figure $3 c$ );

7. Four plates to cover left door wing, two plates per side (Figure $3 c$ );

8. Four plates to cover right door wing, two plates per side (Figure $3 c$ ). 
a)

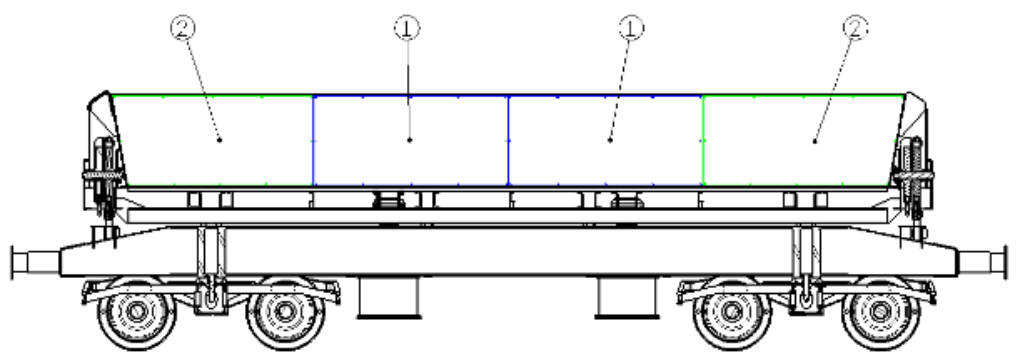

b)

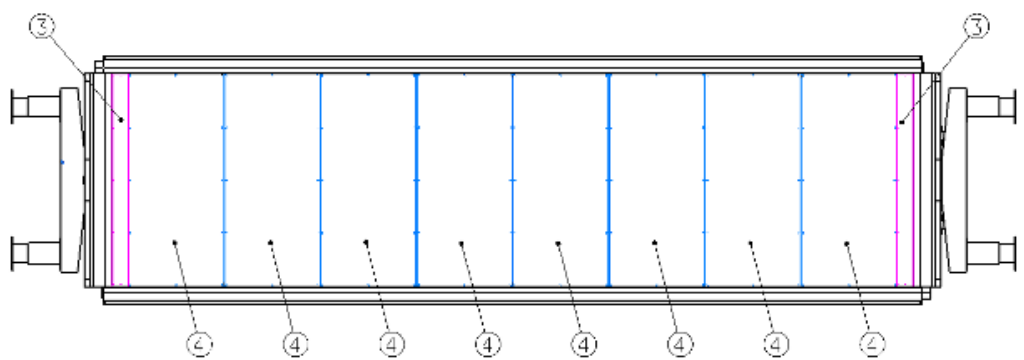

Fig. 2.The arrangement of composite plates - 418V Dumpcar wagon: $a$ ) longitudinal cross-section, b) top view.

a)

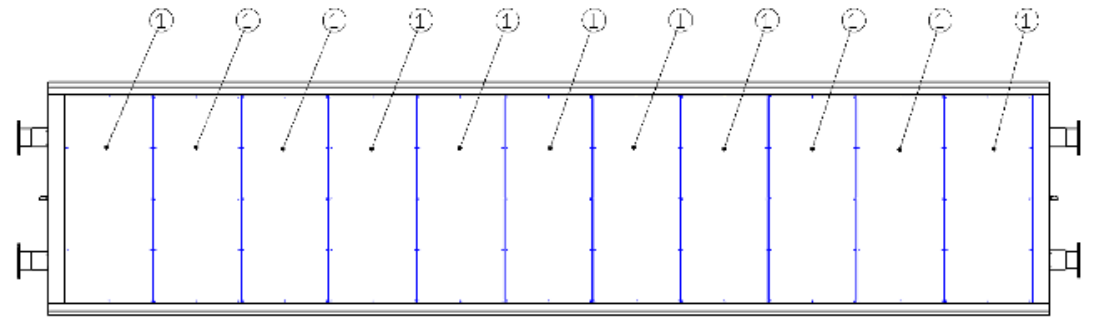

b)

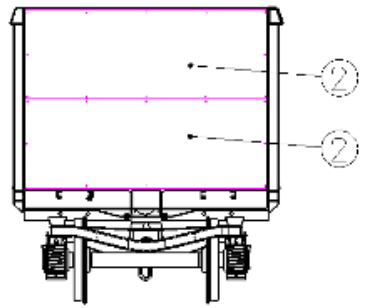

c)

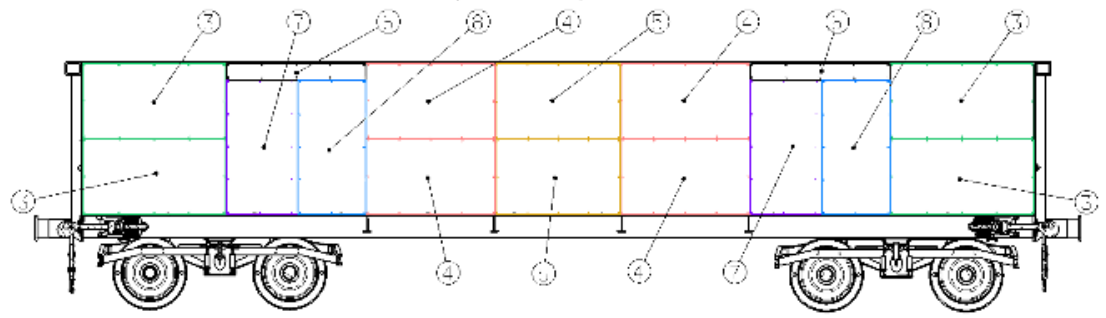

Fig. 3. The arrangement of composite plates - EAOS 1415-A3: $a$ ) top view, $b$ ) transverse crosssection, $c$ ) longitudinal cross-section. 


\section{Conclusions and discussion}

As a response to the needs of the industry company concept of freight wagon modernization described in this paper could contribute to major savings. Developed solution could influence on service time as well as limiting costs of their repairs. CAD software used in this project along others available on the market can providesimplifying design and modification processes due to historical-based design. Complex software such as CATIA V5-6provide tools for effortless modification owning to design parametrization giving the ability to re-design components and assemblies by changing a small number of values. In this paper only a short report of research works concerned with composite modelling and solid model creation using dedicated application, assembly creation with the use of engineering connections, technical documentation creation according to ISO 1101 standard was mentioned.

The proposed solution was verified by a number of laboratory tests as well as test on the real objects during their standard exploitation and results of this works are presented also in other authors' publications [9-11]. Obtained results proved that it can extend the period between repairs of freight cars and improve their maintenance. On the other hand the proposed solution with application of composite panels to the body of the standard freight car during its periodic repair, without necessary to replace the wagon plating, is cost effective juxtaposing with other proposals with application of aluminium alloy or stainless steel [6-8]. The proposed technology can be applied not only in new freight wagons but also in renovated ones in order to prolong the period of exploitation.

\section{References}

1. A. Sękala, G. Kost, A. Dobrzańska-Danikiewicz et al.,IOP Conf. Ser.: Mater.Sci. Eng. 95012134 (2015)

2. K. Jamroziak, M. Bocian, M. Kulisiewicz, J. of Theoret. and Appl. Mechanics, 51(4) 827-835 (2013)

3. P. Ociepka, K. Herbuś, A. Gwiazda, Adv.Materials Research 10361011-1016 (2014)

4. J. Tuma, J. Simek, J. Skuta et al., Springer Proceedings in Physics 139 619-624 (2011)

5. K. Klarecki, D. Rabsztyn, M. Hetmańczyk, Ekspl. i Niezaw. - Maintenance and Reliability, 17(3), 338-344 (2015)

6. Skillingberg M, Green J. (2007) Aluminium Applications in the Rail Industry, Light Metal Age [http://www.aluminum.org/resources/electrical-faqs-and-handbooks/marine, access 31.03.2017]

7. AZO Materials, Applications of Cromgard Stainless Steel in the Railway Industry (2005) [http://www.azom.com/article.aspx?ArticleID=2929, access 31.03.2017]

8. AZO Materials: Developments in Composite Materials for the Rail Industry from TRB Lightweight Structures (2014)

[http://www.azom.com/article.aspx?ArticleID=11061, access 31.03.2017]

9. A. Wróbel, M. Płaczek, A. Buchacz, M. Majzner, Int. J. Materials and Product Technology 50 (3/4) 259-275 (2015)

10. M. Płaczek, A. Wróbel, A. Baier, IOP Conf. Ser.: Mater. Sci. Eng. 145042026 (2016)

11. M. Płaczek, A. Wróbel, A. Buchacz, IOP Conf. Ser.: Mater. Sci. Eng. 145072012 (2016)

12. M. Płaczek, A. Buchacz, A. Wróbel, Eksploatacja i Niezawodnosc - Maintenance and Reliability 17 443-449 (2015)

13. M. Płaczek, A. Wróbel, A. Buchacz, IOP Conf. Series: Materials Science and Engineering 161 012107(2016)

14. A. Wróbel, M. Płaczek, A. Buchacz, Acta Mech. et Automatica, 10 (1) 17-21 (2016) 